\title{
Prevalence of Malaria and Treatment Seeking Behaviours among Pregnant Women in Postconflict Internally Displaced Persons' Camps in Gulu District
}

\author{
Obol James Henry, ${ }^{1}$ Kitara David Lagoro, ${ }^{2}$ and Christopher Garimoi Orach \\ ${ }^{1}$ Department of Public Health, Faculty of Medicine, Gulu University, P.O. Box 166, Gulu, Uganda \\ ${ }^{2}$ Department of Surgery, Gulu University, P.O. Box 166, Gulu, Uganda \\ ${ }^{3}$ Department of Community Health and Behavioural Sciences, Makerere University, P.O. Box 7072, Kampala, Uganda
}

Correspondence should be addressed to Obol James Henry, obolh@yahoo.com

Received 18 October 2011; Accepted 15 November 2011

Academic Editor: D. L. Groll

Copyright ( 92012 Obol James Henry et al. This is an open access article distributed under the Creative Commons Attribution License, which permits unrestricted use, distribution, and reproduction in any medium, provided the original work is properly cited.

\begin{abstract}
Background. Malaria is a serious health problem that contributes greatly to morbidity and mortality in Uganda. It mainly affects pregnant women and children under 5 years of age. Malaria accounts for $9-14 \%$ of inpatient deaths in public and private not-forprofit health facilities in Uganda. Methods. A cross-sectional study using quantitative data collection technique was carried out in Gulu district IDP camps. Proportion to size cluster sampling method was used to determine the numbers of pregnant women to be interviewed per IDP camp. We interviewed 769 pregnant women from 20 IDP camps using consecutive sampling methods by moving to the next nearest household. Results. 372(49\%) of respondents indicated that they had suffered from malaria in the past two months. 348(94\%) respondents got treatment for malaria. 299(86\%) sought treatment from a health facility, 35 (10\%) sought treatment from clinic, and 14(4\%) sought treatment from drug shops. Factors associated with treatment seeking were experience of miscarriage $\left(\chi^{2}=3.87, P\right.$ value $\left.=0.049\right)$ and antenatal visit $\left(\chi^{2}=4.71, P\right.$ value $\left.=0.029\right)$. Conclusion. The prevalence of malaria was high among the respondents at about half. Majority of the respondents sought treatment from health facilities while a few of them sought treatment for malaria from clinic and drug shop. Pregnant women should be advised to seek treatment whenever they have malaria from health facility to ensure that the treatment given is appropriate.
\end{abstract}

\section{Background}

Malaria during pregnancy is a major public health problem in tropical and subtropical regions throughout the world [1, 2]. Malaria causes serious illness and death amongst children and pregnant women [3]. There are between 300 and 500 million malaria infections and 1 million malaria-attributed deaths worldwide each year $[4,5]$. The global malaria burden is not evenly distributed with Sub-Saharan Africa accounting for $90 \%$ of global malaria cases [6-9], and a majority of these cases occur among pregnant women and children $[3,10]$. Malaria adversely impacts on maternal health causing malaria-related anaemia $[11,12]$ and accounts for $20 \%$ of all childhood deaths in Africa [13].

In Uganda, malaria is a serious health problem that contributes greatly to morbidity and mortality. It mainly affects pregnant women and children under 5 years of age
[14-16]. Malaria accounts for $25-40 \%$ of outpatient visits, $20 \%$ of inpatient admissions, and $9-14 \%$ of inpatient deaths in public and private not-for-profit health facilities. Malaria and malaria-related illnesses contribute to $20-23 \%$ of deaths among children aged less than five years [16]. Some of the reasons for this poor state included limited access to adequate treatment of malaria/fever, increasing resistance of malaria parasites to medicines, and incorrect and/or inadequate malaria treatment at home or within communities $[16,17]$. We therefore conducted a cross-sectional study by asking pregnant women verbally whether they have ever suffered from malaria during the past two months prior to the survey in the postconflict internally displaced persons' (IDP) camps in Gulu district. The aim of the study was to establish prevalence of malaria and treatment seeking behaviours among pregnant women in the IDP camps. 
TABLE 1: Socio-demographic characteristics of respondents.

\begin{tabular}{|c|c|c|}
\hline Variable & $\begin{array}{c}\text { Frequencies } \\
n\end{array}$ & $\begin{array}{c}\text { Percentage } \\
(\%)\end{array}$ \\
\hline \multicolumn{3}{|l|}{ Age } \\
\hline $14-25$ & 423 & 55 \\
\hline $26-45$ & 346 & 45 \\
\hline \multicolumn{3}{|c|}{ Have ever attended formal education } \\
\hline Yes & 569 & 74 \\
\hline No & 200 & 26 \\
\hline \multicolumn{3}{|c|}{ Experience of miscarriage } \\
\hline Yes & 126 & 16 \\
\hline No & 640 & 84 \\
\hline \multicolumn{3}{|l|}{ Antenatal visit } \\
\hline Yes & 511 & 67 \\
\hline No & 255 & 33 \\
\hline \multicolumn{3}{|c|}{ Numbers of antenatal visits } \\
\hline 1 Visit & 203 & 40 \\
\hline 2 Visits & 287 & 56 \\
\hline 3 Visits & 021 & 04 \\
\hline \multicolumn{3}{|l|}{ Marital status } \\
\hline Married & 232 & 30 \\
\hline Single & 058 & 08 \\
\hline Cohabiting & 477 & 62 \\
\hline Divorced & 001 & 00 \\
\hline Widowed & 001 & 00 \\
\hline \multicolumn{3}{|l|}{ Gravidity } \\
\hline Multigravidae & 648 & 84 \\
\hline Primigravidae & 121 & 16 \\
\hline \multicolumn{3}{|c|}{ Gestation Age in months } \\
\hline $1-5$ months & 341 & 45 \\
\hline 6-10 months & 420 & 55 \\
\hline
\end{tabular}

\section{Methods}

A cross-sectional study was carried out in Gulu district IDP camps among pregnant women. Gulu district is postconflict area due to the over two-decade arm conflict. The district had 31 IDP camps [18] and 10,888 pregnancies [19] from July 2007 to June 2008. All the 31 IDP camps were taken as clusters. We selected randomly 20 IDP camps as clusters for survey using simple random sampling without replacement technique. The name of each of the IDP camp was written on a piece of paper that was later folded and put into nontransparent polythene bag. The folded pieces of papers with the name of IDP camp were picked once at a time without replacement until the 20 IDP camps to be surveyed were reached. To determine the number of pregnant women to be surveyed in each of the 20IDP camps, we used proportion to size cluster sampling method. We divided the number of pregnant women using the $2007 / 08$ population of pregnant women in the IDP camps with the total numbers
TABLE 2: Malaria and treatment seeking behaviour.

\begin{tabular}{lcc}
\hline Variable & $\begin{array}{c}\text { Frequency } \\
n\end{array}$ & $\begin{array}{c}\text { Percentage } \\
\%\end{array}$ \\
\hline Suffered from malaria in the past 2 Months & & \\
$\quad$ No & 384 & 51 \\
$\quad$ Yes & 372 & 49 \\
Did you get treatment & & \\
$\quad$ Yes & 348 & 94 \\
No & 024 & 06 \\
Source of malaria treatment & & \\
Health facility & 299 & 86 \\
Clinic & 035 & 10 \\
$\quad$ Drug shop & 014 & 04 \\
Village health team & 000 & 00 \\
Traditional healer & 000 & 00 \\
\hline
\end{tabular}

of pregnant women in each of the 20 IDP camps. We then multiply this proportion with our sample size of 769 pregnant women to give us the numbers of pregnant women per IDP camp to be sampled for survey. In each of the IDP camps, we determined the centre first. The direction of movement was where the bottle top faces after spinning on the ground. All the households in that direction were given a number. A corresponding number was picked blindly from a nontransparent polythene bag to determine the starting household. We then used consecutive sampling method by moving to the next nearest household to interview the 769 pregnant women in the 20 IDP camps. The inclusion criteria were pregnant women who gave self-report of carrying pregnancy, being residents of the 20 selected IDP camps and present on the interview date after giving a written informed consent to participate in the study. Pregnant women who were seriously sick or were in labour were excluded. The study was approved by the Faculty of Medicine Research and Ethic Committee, Makerere University, that granted permission to study pregnant women less than 18 years old as emancipated minors.

Pregnant women were asked verbally whether they have experience an episode of malaria in the past two months prior to the survey and whether they sought treatment and the sources of treatment. This was then used to determine the prevalence of malaria among pregnant women in the past two months prior to the survey and their treatment seeking behaviours. We used a semistructured questionnaire that was translated into Acholi with the help of an expert linguistic and back translated into English. The questionnaire was pretested and then administered by trained research assistants who were fluent in the local language (Acholi). The questionnaire was interviewer administer whereby respondents were asked questions and their responses were recorded by the research assistants. The collected data was entered into Epidata version 3.1 cleaned, edited, coded, and exported to STATA 11 for analysis. Continuous variables were summarised using means and categorical variables were displayed into tables for general description. 
TABLE 3: Chi-square test for factors associated with treatment seeking for malaria.

\begin{tabular}{|c|c|c|c|c|}
\hline \multirow[t]{2}{*}{ Variable } & \multicolumn{2}{|c|}{ Got treatment } & \multirow[t]{2}{*}{$\chi^{2}$} & \multirow[t]{2}{*}{$P$ value } \\
\hline & Yes (\%) & No (\%) & & \\
\hline \multicolumn{5}{|l|}{ Age group } \\
\hline $14-25$ & $182(99)$ & $012(01)$ & \multirow{2}{*}{0.38} & \multirow{2}{*}{0.535} \\
\hline $26-45$ & $165(92)$ & $014(08)$ & & \\
\hline \multicolumn{5}{|c|}{ Have ever attended formal education } \\
\hline Yes & $250(92)$ & $022(08)$ & \multirow{2}{*}{1.94} & \multirow{2}{*}{0.164} \\
\hline No & $097(93)$ & $004(07)$ & & \\
\hline \multicolumn{5}{|l|}{ Experience of miscarriage } \\
\hline Yes & $065(88)$ & $009(12)$ & \multirow{2}{*}{3.87} & \multirow{2}{*}{0.049} \\
\hline No & $283(94)$ & $017(06)$ & & \\
\hline \multicolumn{5}{|l|}{ Antenatal visit } \\
\hline Yes & $245(95)$ & $013(05)$ & \multirow{2}{*}{4.71} & \multirow{2}{*}{0.029} \\
\hline No & $103(89)$ & $013(11)$ & & \\
\hline \multicolumn{5}{|l|}{ Numbers of antenatal visits } \\
\hline 1 Visit & $107(94)$ & $007(06)$ & \multirow{3}{*}{0.63} & \multirow{3}{*}{0.729} \\
\hline 2 Visits & $132(96)$ & $006(04)$ & & \\
\hline 3 Visits & $004(100)$ & $000(00)$ & & \\
\hline \multicolumn{5}{|l|}{ Marital status } \\
\hline Married/cohabiting & $329(93)$ & $023(07)$ & \multirow{2}{*}{1.61} & \multirow{2}{*}{0.204} \\
\hline Single/divorced/widowed & $019(86)$ & $003(14)$ & & \\
\hline \multicolumn{5}{|l|}{ Gravidity } \\
\hline Multigravidae & $314(94)$ & $021(06)$ & \multirow{2}{*}{2.5} & \multirow{2}{*}{0.114} \\
\hline Primigravidae & $033(87)$ & $005(13)$ & & \\
\hline \multicolumn{5}{|l|}{ Gestation age in months } \\
\hline 1-5 Months & $149(91)$ & $015(09)$ & \multirow{2}{*}{2.03} & \multirow{2}{*}{0.155} \\
\hline 6-10 Months & $195(95)$ & $011(05)$ & & \\
\hline
\end{tabular}

\section{Results}

We interviewed a total of 769 pregnant women with age ranging from 14 to 45 years with a mean age of 25.3 years and standard deviation (SD) of 6.2. The gestation age ranges from 1 to 10 months with the mean gestation age of 5.7 months and standard deviation of 2.2 months. Table 1 summarises socio-demographic characteristics of respondents.

3.1. Malaria and Treatment Seeking Behaviour. 372 (49\%) of respondents had suffered from malaria and 348 (94\%) of those who suffered from malaria in the past two months got treatment. Table 2 summarises the result for malaria treatment seeking behaviour.

3.2. Factors Associated with Malaria Treatment Seeking. Experience of miscarriage and antenatal visit was significantly associated with treatment seeking for malaria. Table 3 summarises the association between treatment seeking and sociodemographic characteristics of respondents.

\section{Discussion}

About half of the pregnant women reported that they have suffered from malaria in the past two months and out of this majority got treatment while a few did not get treatment for malaria. The most common source of treatment mentioned by respondents was health facility. This observation is similar with other studies done in Tanzania [20-22], Eritrea [23], and Sudan [24]. None of the pregnant women indicated that they have visited traditional healers as reported in other studies [25-27] or village health team (VHT) member to seek for treatment. Also, none of the respondent mentioned that they use herbs to treat malaria as reported in other studies [21,27]. Other sources of malaria treatment such as clinics and drug shops were also mentioned by pregnant women. This act of self-treatment is consistent with findings from study done in other part of Uganda [28] and other studies done in India [29], Tanzania [22], and Bangladesh [25]. A few of the pregnant women reported not to have got treatment for malaria. This could be due to drug stock out at the health facilities as noted in the annual health sector performance report [16].

The presence study shows that experience of miscarriage by pregnant women was significantly associated with seeking treatment for malaria by pregnant women $\left(\chi^{2}=3.87, P\right.$ value $=0.049)$. This could be because pregnant women who had experience miscarriage were told the cause or could have experienced malaria prior to her miscarriage. This then makes her more likely to seek treatment for malaria to avoid 
similar occurrence. Also, antenatal visit was significantly associated with seeking treatment for malaria. This could be because during antenatal visit, pregnant women who complain that they were sick of malaria were treated. Also, during antenatal visit, pregnant women normally undergo health education session before being seen by midwife. This health education session makes her more enlighten about common health problem for pregnant women and she is more likely to seek treatment for malaria whenever she experiences malaria signs and symptoms.

The main limitations of our study that we used were asking pregnant women verbally whether they have experienced an episode of malaria to determine the prevalence of malaria. This could have bias the findings since any fever that was experienced by the pregnant women could have been treated as malaria. However, in light of other studies, our findings indicated a better result because none of the pregnant women had used local herbs or consulted witch doctor as reported by other studies. The majority reported using health facilities for treatment which is a good step for public health campaign.

\section{Conclusion and Recommendation}

The prevalence of malaria is high at about half among the respondents. The majority of the respondents sought treatment from health facilities. However, few pregnant women got treatment from clinics and drug shops or did not get treatment for malaria. Pregnant women should be advised to seek treatment whenever they have malaria from health facility. This is to ensure that the treatment given is appropriate.

\section{Conflict of Interests}

The authors declare that they have no conflict of interests.

\section{Authors' Contributions}

O. J. Henry participated in the conception, design, and implementation of the study, statistical analysis, interpretation, and drafting of manuscript. D. L. Kitara participated in study design, interpretation and drafting of manuscript. C. G. Orach participated in study conception, design, statistical analysis, interpretation, and drafting of manuscript. All authors read and approved the final manuscript.

\section{Acknowledgments}

The authors would like to express their gratitude to the Belgian Technical Cooperation in Uganda for the scholarship given to Mr. O. J. Henry to fund this study. they specially thank the pregnant women for accepting to participate in this study. Special thanks go to Makerere University, Faculty of Medicine Research, and Ethics Committee for the ethical clearance and Gulu District Health Department for giving permission to conduct the study.

\section{References}

[1] F. Nosten, F. Terkuile, and L. Malankiri, "Malaria in pregnancy in an area of unstable endemicity," Transactions of the Royal Society of Tropical Medicine and Hygiene, vol. 48, pp. 154-160, 1991.

[2] S. P. Yadav, "A study of treatment seeking behaviour for malaria and its management in febrile children in rural part of desert, Rajasthan, India," Journal of Vector Borne Diseases, vol. 47, no. 4, pp. 235-242, 2010.

[3] WHO, "Malaria control today: current WHO recommendations," RBM Department, 2005.

[4] WHO, "Children and Malaria: Roll Back Malaria Fact Sheet," 2002.

[5] B. L. Nahlen, J. P. Clark, and D. Alnwick, "Insecticide-treated bed nets," American Journal of Tropical Medicine and Hygiene, vol. 68, supplement 4, pp. 1-2, 2003.

[6] L. Moluneaix and C. Cramicara, "Research on Epidemiology and Control of Malaria in the Sudan Savannah of West Africa," The Garth Project, WHO, Geneva, Switzerland, 1980.

[7] World Health Organisation, "Implementation of the Global malaria control strategy," Report of a WHO Study Group, General, 1993.

[8] World Health Organisation, "General Guidelines for Methodologies on Research and Evaluation in Traditional Medicine," News letter, vol. 15, no. 2, 2000.

[9] WHO, "Malaria in Pregnancy: Roll Back Malaria Factsheet," 2002.

[10] R. W. Steketee, J. J. Wirima, L. Slutsker, D. L. Heymann, and J. G. Breman, "The problem of malaria and malaria control in pregnancy in sub-Saharan Africa," American Journal of Tropical Medicine and Hygiene, vol. 55, supplement 1, pp. 27, 1996.

[11] L. S. Nair and A. S. Nair, "Effects of malaria infection on pregnancy," Indian Journal of Malariology, vol. 30, no. 4, pp. 207-214, 1993.

[12] F. P. Mockenhaupt, B. Rong, M. Günther et al., "Anaemia in pregnant Ghanaian women: importance of malaria, iron deficiency and haemoglobinopathies," Transactions of the Royal Society of Tropical Medicine and Hygiene, vol. 94, no. 5, pp. 477-483, 2000.

[13] WHO, "Roll Back Malaria: Global Strategic Plan: Roll Back Malaria, 2005-2015," Geneva, Switzerland, Roll Back Malaria Partnership, 2005.

[14] Ministry of Health, "The National Health Policy," Uganda, 1999.

[15] Ministry of Health, "Implementing Guidelines for the National Home Based Management of Fever Strategy," Uganda, 2002.

[16] Ministry of Health, "Annual Health Sector Performance Report 2009/10," Uganda.

[17] Ministry of Health, "A Review of the Situation of Malaria Prevention and Control in Uganda," Uganda, 2005.

[18] United Nation High Commissioner for Refugee. Unpublished data from Gulu office, 2008.

[19] Gulu district Health Management and Information System record. Unpublished data from July 2007-June 2008.

[20] D. de Savigny, C. Mayombana, E. Mwageni et al., "Careseeking patterns for fatal malaria in Tanzania," Malaria Journal, vol. 3, article 27, 2004.

[21] L. E. G. Mboera, M. R. S. Mlozi, K. P. Senkoro et al., "Malaria and agriculture in Tanzania. Impact of land use 
and agricultural practices on Malaria in Mvomero district," National Institute for Medical Research, Dar es Salaam, Tanzania, 2007.

[22] D. M. Humphrey, O. Emmanuel, M. Wilhellmus et al., "Knowledge, attitudes, and practices about Malaria and its control in rural Northwest Tanzania," Malaria Research and Treatment, vol. 2010, Article ID 794261, 9 pages, 2010.

[23] H. Hans, G. Tewolde, M. Selam, M. Jacob, and G. Andemariam, "Knowledge, attitudes and practices (KAP) about malaria among people visiting Referral Hospitals of Eritrea in 2008," Journal of Eritrean Medical Association, pp. 42-46, 2008.

[24] K. A. Elmardi, A. M. Noor, S. Githinji, T. M. Abdelgadir, E. M. Malik, and R. W. Snow, "Self-reported fever, treatment actions and malaria infection prevalence in the northern states of Sudan," Malaria Journal, vol. 10, article 128, 2011.

[25] S. M. Ahmed, R. Haque, U. Haque, and A. Hossain, "Knowledge on the transmission, prevention and treatment of malaria among two endemic populations of Bangladesh and their health-seeking behaviour," Malaria Journal, vol. 8, no. 1, article 173, 2009.

[26] C. K. Ahorlu, S. K. Dunyo, E. A. Afari, K. A. Koram, and F. K. Nkrumah, "Malaria-related beliefs and behaviour in southern Ghana: implications for treatment, prevention and control," Tropical Medicine and International Health, vol. 2, no. 5, pp. 488-499, 1997.

[27] P. O. Sumba, S. L. Wong, H. K. Kanzaria, K. A. Johnson, and C. C. John, "Malaria treatment-seeking behaviour and recovery from malaria in a highland area of Kenya," Malaria Journal, vol. 7, article 245, 2008.

[28] A. K. Mbonye, S. Neema, and P. Magnussen, "Treatmentseeking practices for malaria in pregnancy among rural women in Mukono district, Uganda," Journal of Biosocial Science, vol. 38, no. 2, pp. 221-237, 2006.

[29] L. L. Sabin, A. Rizal, M. I. Brooks et al., "Attitudes, knowledge, and practices regarding malaria prevention and treatment among pregnant women in eastern India," American Journal of Tropical Medicine and Hygiene, vol. 82, no. 6, pp. 1010-1016, 2010. 


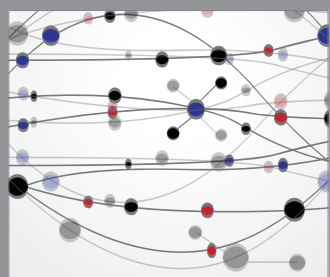

The Scientific World Journal
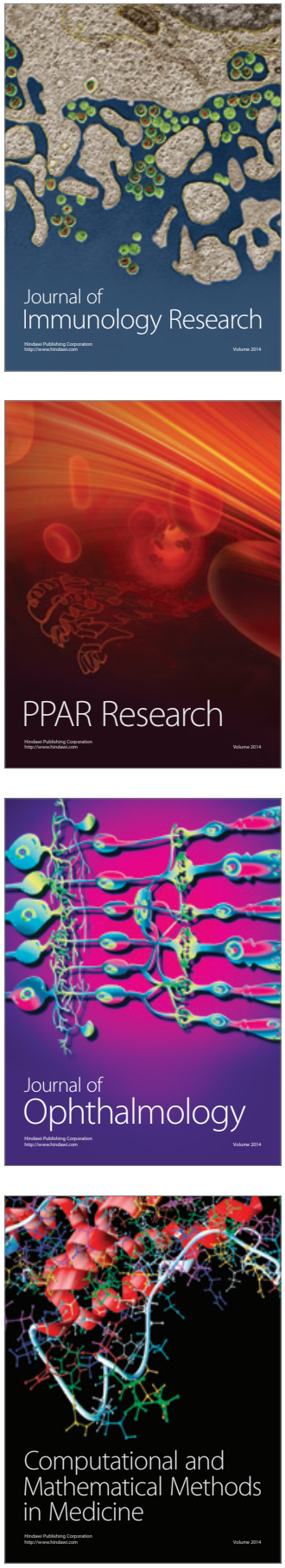

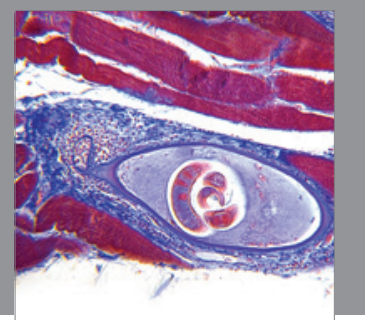

Gastroenterology

Research and Practice
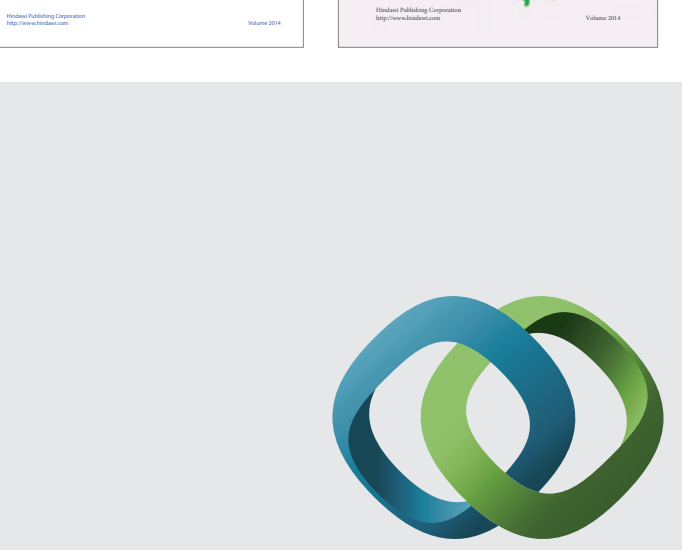

\section{Hindawi}

Submit your manuscripts at

http://www.hindawi.com
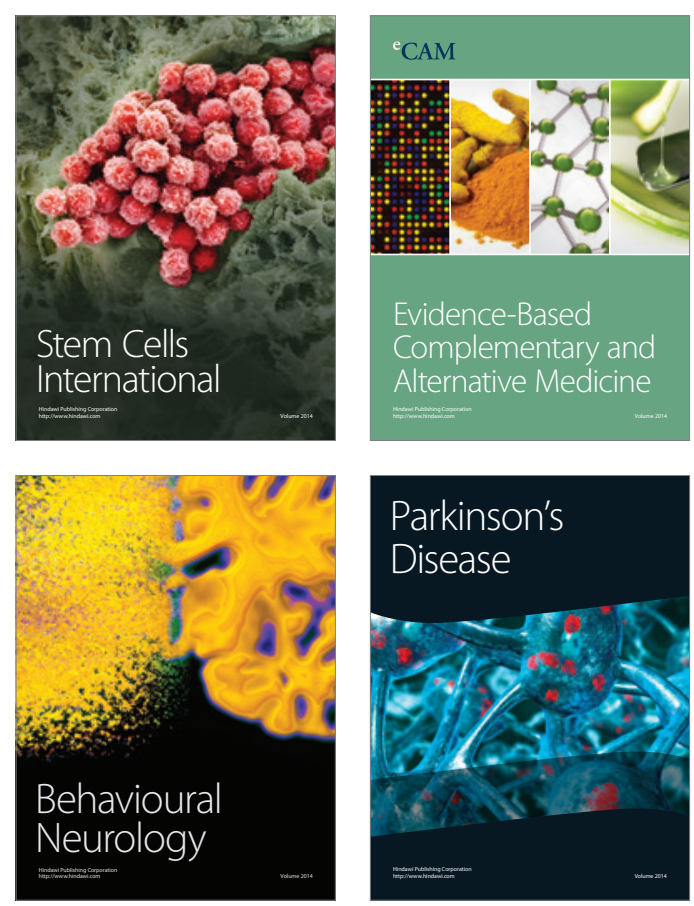

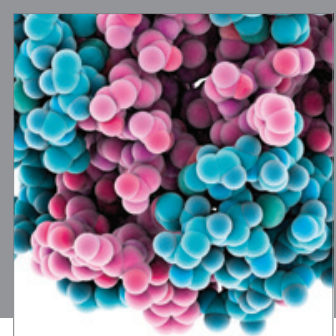

Journal of
Diabetes Research

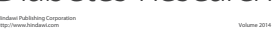

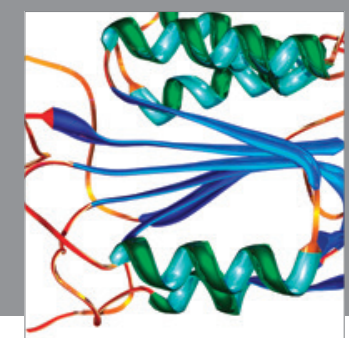

Disease Markers
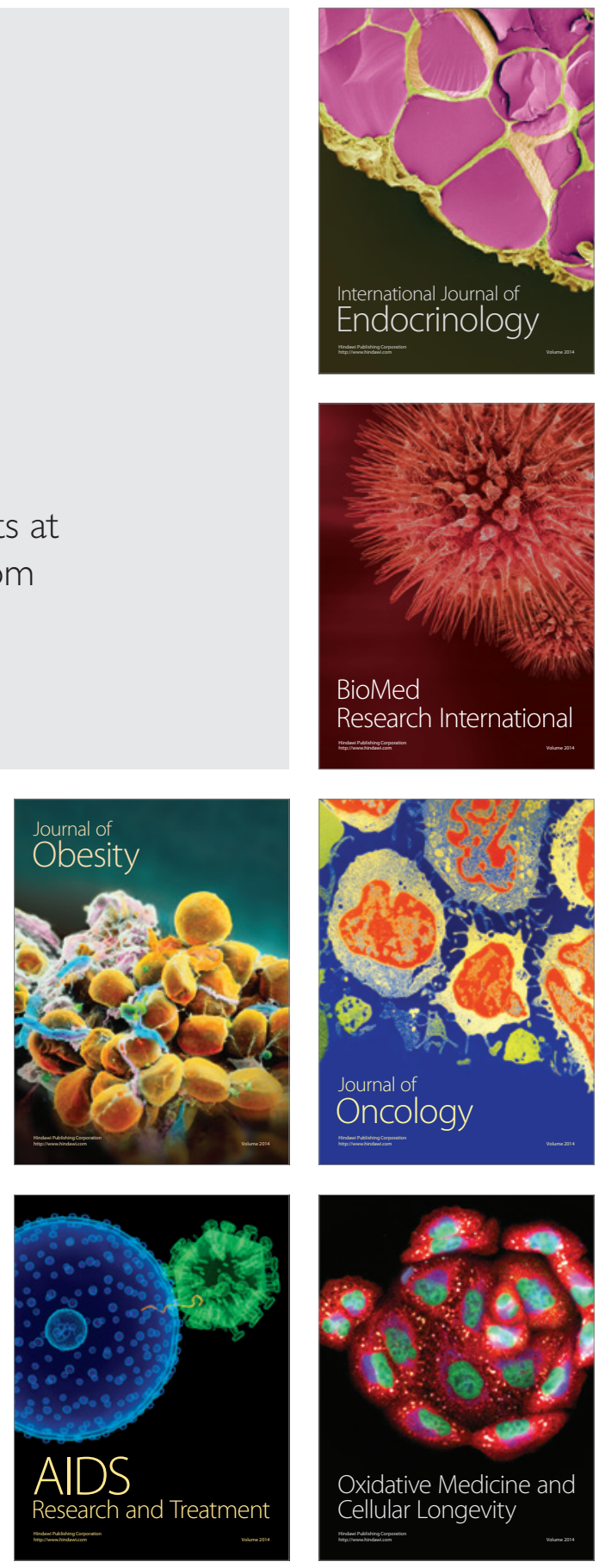